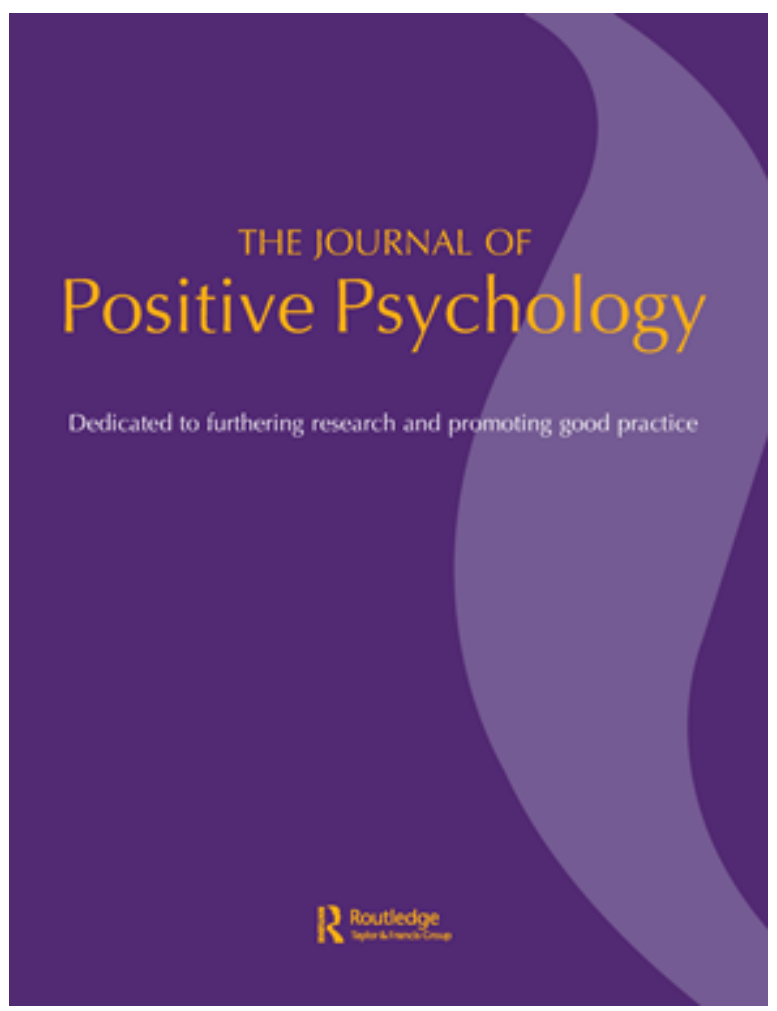

\title{
A Hermeneutic Phenomenological Exploration of Feeling Joyful
}

\begin{tabular}{|c|c|}
\hline Journal: & The Journal of Positive Psychology \\
\hline Manuscript ID & RPOS-2019-0557 \\
\hline Manuscript Type: & Special Issue Paper \\
\hline $\begin{array}{r}\text { Date Submitted by the } \\
\text { Author: }\end{array}$ & 05-Nov-2019 \\
\hline Complete List of Authors: & $\begin{array}{l}\text { Chauhan, Priyanka; University of Huddersfield, } \\
\text { Leeming, Dawn; University of Huddersfield, Psychology } \\
\text { King, Nigel; University of Huddersfield }\end{array}$ \\
\hline Keywords: & joy, happiness \\
\hline Keywords (author supplied): & emotion, human science method \\
\hline
\end{tabular}

\section{SCHOLARONE \\ Manuscripts}




\section{A Hermeneutic Phenomenological Exploration of Feeling Joyful}

Priyanka Hope Chauhan - Department of Psychology, University of Huddersfield

Dr Dawn Leeming - Director of Graduate Education, Department of Psychology, University of Huddersfield

Professor Nigel King - Professor in Applied Psychology and Dean of the Graduate School, University of Huddersfield

Name: Priyanka Hope Chauhan, Address: University of Huddersfield, Queensgate, Huddersfield, HD1 3DH, Phone: 07855460618, Email: priyanka.hope.chauhan@gmail.com

Name: Dr Dawn Leeming, Address: University of Huddersfield, Queensgate, Huddersfield, HD1 3DH, Phone: 01484 473545, Email: D.Leeming@hud.ac.uk

Name: Professor Nigel King, Address: University of Huddersfield, Queensgate, Huddersfield, HD1 3DH, Phone: 01484 472812, Email: n.king@hud.ac.uk 


\begin{abstract}
This paper discusses our use of a hermeneutic phenomenological methodology to explore the lived experience of feeling joyful. Semi-structured interviews were used to discuss two contrasting experiences of joy for each participant. Analysis was informed by van Manen's human science method, facilitated by King's template analysis. Our findings suggest that joy was a profoundly meaningful sense of positivity. Sometimes this feeling was fleeting, at other times it was described as a longer lasting experience. Regardless of duration, joy involved a desire to relinquish control which could be expressed as a freedom of movement, and could be enabled by the security that significant others provided. We discuss our findings in relation to distinctions previously drawn in the literature between happiness and joy and argue that, despite differences in experiences, the participants' accounts support an understanding of joy as a meaningful and social phenomenon which, though often unexpected, requires intentional engagement.
\end{abstract}

Keywords: joy, human science method, happiness, emotion 


\section{A Hermeneutic Phenomenological Exploration of Feeling Joyful}

Paradoxically, some of the emotional experiences that we value most have been given least attention within academic psychology. The development of positive psychology (e.g. Seligman \& Csikszentmihalyi, 2000) has sought to rectify this but, with the exception of Maslow's work (e.g. 1964) on peak experiences, joy has received relatively little attention from researchers. This paper explores the value of a phenomenological approach for investigating the subjective experience and meaning of feeling joyful.

\section{Our approach to emotion}

Although emotions are recognised as a fundamental part of what it means to be human (Barbalet, 2006; Slaby 2008), psychologists have not always agreed about the nature of emotion and hence the best ways to investigate emotional phenomena (Barrett, 2006). An objectivist approach to emotion has dominated much of the psychological literature, with the aims of defining emotion categories, proposing underlying cognitive and neurobiological mechanisms and looking for cause and effect relationships between emotion-related phenomena, often with the further aim of developing methods for modifying negative emotional experiences. However, other emotion theorists and researchers have argued for the value of approaches to researching emotion which foreground the lived experience of emotion and explore the personal meaning and social significance of emotional experiences (e.g. Frijda, 2005; Eatough \& Smith, 2006). In relation to positive psychology, Rich (2017) has recently proposed a corrective shift towards more frequent use of methods which enable the complexity and context of positive emotional experiences to be captured, by collecting participant narratives. In exploring experiences of joy, we take this first 
person lived approach in the hope that this will develop understanding of the nature and significance of feeling joyful.

Sartre (1939/1971) was one of the first to argue against the value of examining emotions as decontextualized phenomena which could be reduced to their component parts. For him, such an approach misses what is most human and significant about emotional experiences. Instead, Sartre argued, emotion should be understood as a way-of-being in the world that has meaning for the individual. Drawing on Husserl's (1925/1962) notion of intentionality, Sartre noted that emotion is always about something in the world and argued that becoming emotional involves a transformation of one's relationship to, and awareness of, the world and a change in our way of responding to the world. Moreover, for Sartre, emotion was something we do rather than something that happens to us. This suggests not only the value of researching emotion from a first-person perspective, but also the value of investigating emotion as a contextualised phenomenon, in a manner which does not divorce the feeling, acting subject and the object of emotion. This has certainly been the understanding of several psychological theorists who have argued that becoming emotional is not simply a changed internal state but part of meaningful social interaction and that it is useful to investigate emotion as such. For example, Averill (1982) characterises emotion as the enactment of a transitory social role, while Parkinson (1996) argues that becoming emotional involves making identity claims, whether to an internal or external audience.

Conceiving of emotion as, at least in part, a form of action further underscores the value of a holistic approach which does not assume a simple cause-and-effect relationship between internal states and emotional behaviour. Merleau Ponty (1945/1962) argued strongly that emotional behaviour should not be viewed as separate from emotion but as an embodiment of the 
emotion. It is through the body that we experience and understand the world and also act on the world. Similarly, Parkinson, Fischer \& Manstead (2005) characterise emotions as 'embodied actions and reactions' (p.16), rather than a cause of such actions, and Frijda (2005) argues that action readiness is part of emotional experiences, shaping our orientation to and understanding of the world. Therefore, following this body of work on the integrated nature of emotional experiences, this article investigates experiences of feeling joyful from a first-person holistic perspective.

\section{Research on joy}

Despite there being no universally agreed-upon definition of joy (Cottrell, 2016), there is now a small body of research which has explored the phenomenon of joy holistically and experientially or through self-report measures. We can, therefore, begin to understand a little of what it feels like to be joyful. In line with Close's (1981) suggestion that joy resembles Maslow's (1964) notion of peak experience, Hoffman, Kaneshiro \& Compton (2012) examined peak experiences by asking middle-aged Americans to reflect on a recent joyful experience. They found that joy was most commonly experienced with loved ones, identifying the feeling of joy as one that is often experienced socially. Both Cottrell's (2016) concept analysis and Robbin's (2006) phenomenological study support this idea. They found that joy is often an experience that involves a deeper connection to others or the world and also a sense of awareness and fulfilment, and playful movement such as dancing or clapping. Additionally, both studies indicate that joy is short-lived and often experienced as unintentional. As a result, Cottrell (2016) claims that joy is fundamentally different from happiness. Unlike happiness, joy is not a state of mind that individuals work towards, but rather it is accidental (Cottrell, 2016). Furthermore, in the moment of feeling joyful, participants in Robbin's (2006) study described a feeling of freedom in the self, 
which resulted from the complete absence of stress or worry. In a recent self-report study of joy and gratitude, Watkins, Emmons, Greaves \& Bell (2017) carried out a factor analysis of selfreport measures of joy and other positive emotions, suggesting that joy should be considered a distinct positive emotion. Together this limited body of research suggests that Joy, might be viewed as a more intense and heightened feeling of positivity than happiness (Sloan, 2011).

Some researchers argue that there is similarity between the feeling of joy and Csikszentmihalyis's (1991) idea of flow (Cottrell, 2016; Robbins, 2005/6). In the experience of flow and joy, the individual is immersed in a specific task or moment and feels a sense of fulfilment in what they are doing, without any focus on reaching goals or seeking achievement. In contrast, van Deurzen (1997) and Sartre (1939/1971) have both suggested that an individual feels joyful when they become one with something they have deeply desired and that has become a reality. Although these two views are not entirely incompatible, they suggest differing expectations regarding the extent to which joy is likely to be part of purposeful activity. This could be explained by there being different experiences of joy. In support of this suggestion, Watkins, Emmons, Greaves \& Bell(2017) found some evidence to suggest that joy may be either a momentary or an enduring feeling, though further research is required to explore the nature of experiences of joy which are temporally varied.

Sartre's and van Deurzen's view, in line with the general approach to emotion outlined above, indicates that joy is about something that is personally meaningful to an individual. However, the few studies with an explicit focus on understanding experiences of joy, for example Robbins (2006) and Watkins, Emmons, Greaves \& Bell (2017) have not included exploration of what, in particular, the individual feels joyful about. Sloan (2011) emphasises the importance of examining the object of joy, because in doing so it may help to clarify or shed 
light on the meaning of this phenomenon. For phenomenology, the intentional nature of experience means that in seeking to understand it as researchers we must always consider both the "what" and the "how". Therefore, in order to enable a contextualised understanding of an emotional experience it is essential to explore the relationship between the feeling and object of the feeling (Sartre, 1939/1971). In this study, therefore, we chose to explore the experience of feeling joyful by collecting accounts of joy which enabled us to examine the context and focus of the experience and the participants' interpretations of feeling joyful.

\section{Methodology and methods}

Phenomenology was the overarching methodological approach taken to investigate the experience of feeling joyful. Within this, we chose to adopt a hermeneutic position. Hermeneutic phenomenology, as outlined by Heidegger and developed as a research approach by scholars such as van Manen (2016), aims to understand and describe an experience through interpretation (Finlay, 2012). The hermeneutic phenomenology methodological approach recognises that description of an experiences is inevitably embedded with one's interpretation of it (Finlay, 2012). In contrast to this, descriptive phenomenology asserts that each phenomenon holds a universal essence or structure that can be discovered via removing one's preconceptions (Giorgi, 1985). Although Our methodological approach did include bracketing of preconceptions to get closer to the lived experience, we maintained a reflexive approach on the understanding that this can never be completely achieved, thus focusing on interpretation and reflexive engagement of the participants' lifeworld as a way to reveal meaning about the lived experience of feeling joyful.

Van Manen's (2016) work was drawn upon to inform our method as his approach is in accordance with our chosen methodological position. His human science method to studying 
human experience suggests six methodological activities [table 1 here]; these provide guidance throughout the whole research process, from the choice of research topic, to data collection, analysis and writing up of the findings, and are inherently tailored to the underpinnings of hermeneutic phenomenology. Through the process of bracketing and interpretation, van Manen (2016) encourages researchers to identify qualities that make the phenomenon what it is - he describes these as "essential themes". Nonetheless, he recognises that the structure of the phenomenon may vary across time and context.

Phenomenological research puts a premium on exploring specific examples of lived experience in depth, rather than seeking to identify commonalities across a larger number of cases. It is therefore appropriate to work with small samples, often in single figures Robinson, 2015; Smith, Flowers \& Larkin, 2009). Following ethical approval two men and two women (ages 21-22) [table 2 here] were invited through personal contact to take part in individual semistructured interviews. Prior to the interview, participants were asked to identify two contrasting examples of a time they felt joyful that they were comfortable to discuss in some detail. During the interview they were then prompted to explore and describe their concrete and real-life experiences of feeling joyful. This was in keeping with van Manen's recommendation that experience is investigated 'as it is lived rather than conceptualised' (van Manen, 2016, p. 30). The interviews were then transcribed for analysis, where all names have been replaced with a pseudonym.

In order to facilitate van Manen's proposed methodological activity of 'reflecting on essential themes' (van Manen, 2016, p. 32), Template Analysis (TA) was used to assist in the identification and organisation of initial themes and sub-themes (King, 2012). TA offers researchers flexibility, thus is in keeping with van Manen's approach as it enables modification 
to the analytical procedure according to the needs of the study. For example, an initial hierarchical template of a thematic structure was constructed rather than using a priori themes from existing literature. We did this via inductive coding of one of the two accounts of feeling joyful provided by each of the participants. This initial template was then used to code the second set of participant examples. The template was then modified and extended until the themes and sub-themes were judged by the first and second authors to capture the key features of all the transcripts.

A more in-depth analysis and discussion of the template was then carried out. Through the 'art of writing and rewriting' (van Manen, 2016, p. 32) the finalised template was used to explore and reflect on themes until top-level themes were developed that were felt to characterise the essential structure of the participants' accounts of feeling joyful. Analysis of these themes by all three authors took place alongside reflection on existing psychological literature on joy to ensure a balance of both 'parts and whole' (van Manen, 2016, p. 33) of the phenomenon and research context.

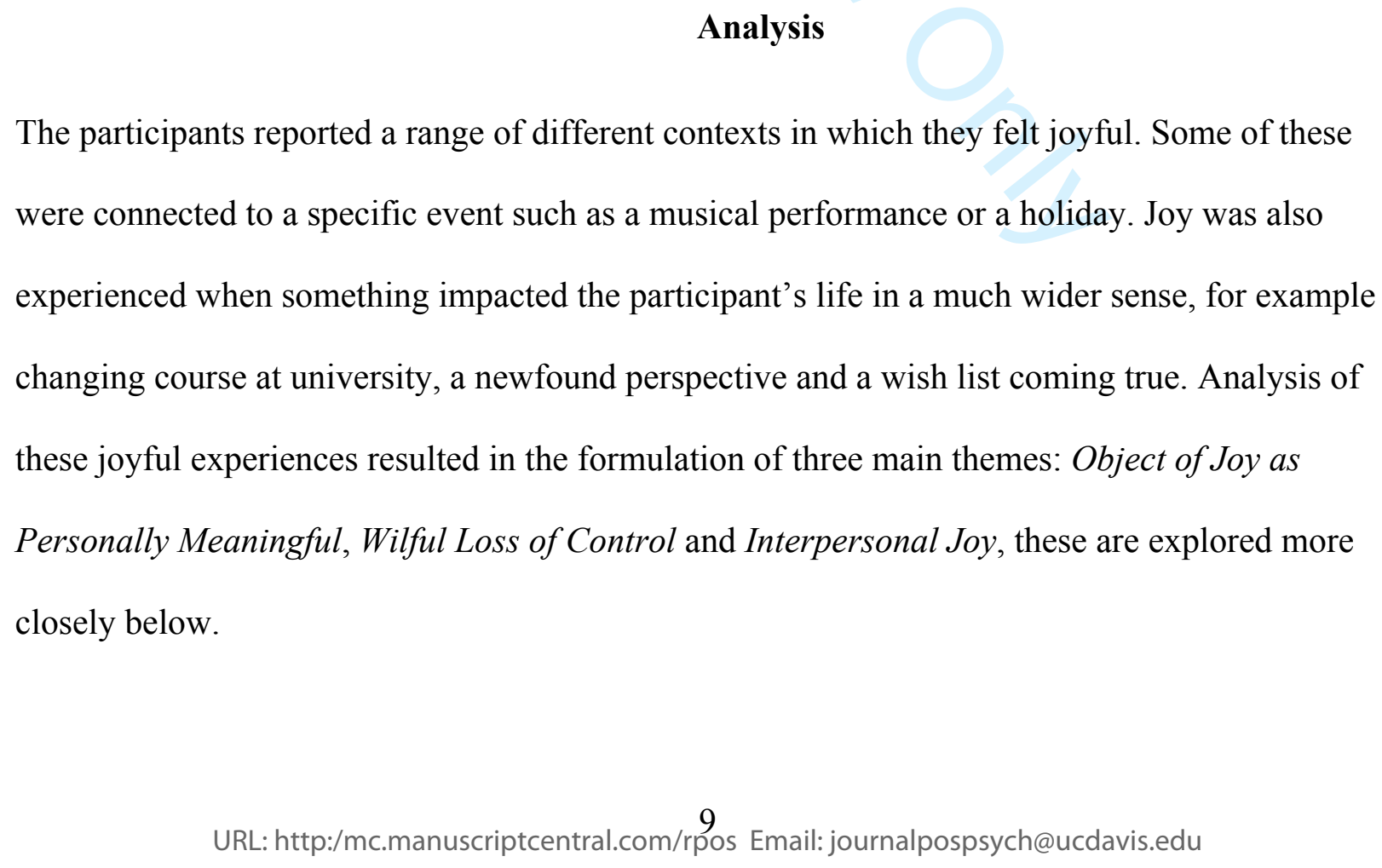


Object of Joy as Personally Meaningful. Despite there being some variation in the context in which joy was experienced, the object of joy was always personally meaningful and important to the individual. The experience of joy, therefore, relied greatly upon the participant's subjective interpretation and meaning making. Additionally, some variation was found in the experience of feeling joyful, particularly regarding the duration, with some experiences being short-lived e.g. seeing a rock band perform and spending a weekend with friends while others were long lasting e.g. changing course at university and a new-found perception of growing old. When the object of joy was short-lived, the participants described an intense and consuming feeling of positivity. In that moment of joy, any unpleasantness or worry disappeared. Similarly, when the object of joy was long-lived, the participants reported an intense feeling of positivity. However, these experiences differed slightly in that joy was directed towards a hopefulness for the future rather than being solely a feeling of positivity in that moment.

Many of the participants described a profound connection with the object or event that evoked their feeling of joyfulness. For Mia, the experience of being in the presence of a rock band that held such significance to her was so powerful that it transformed feelings of irritation and discomfort to feelings of liberation and positivity.

They are quite depressing but somehow their music means a lot and I'm not sure how but erm that's why I felt so like entranced and I forgot where everything was around me and it's because like it was DEEP. There was a connection and I was in a Coldplay bubble (laughs). Also, BEING annoyed standing in the rain to being embracing it when he was 
singing and then you were actually loving the rain. We were soaked, frozen, but it flips it because of the atmosphere and the setting became positive.

As seen in Mia's quote above, she and many of the other participants identified a feeling of mesmerisation and being entranced when joyful. This occurred particularly during short-lived experiences of joy at a specific event, thus revealing that temporary experiences of joy are often connected to a specific moment in space and time. In contrast, this was not necessarily the case when joy was a longer lasting experience as it did not seem to involve a specific physical context. Instead, the feeling of joyfulness derived from a realisation, new understanding or outlook. As a result it appeared to be a transformative and expanding feeling of joyfulness.

Realising that I had actually done most of the things on my list changed my outlook on life because I felt that when I stopped trying to do them that's when I accomplished them. I kind of changed my perspective as well because I have always been worried about the future after university but now I'm still worried a little bit but I am not as worried because I think that some things do happen for a reason. I don't mean that things are set out for us but that life gives us opportunities and choices, and I'll either reject it or get a new one or I'll take it and go down that direction in life. I think I felt joyful the most because things were finally falling into synch and place, it was like the perfect balance in life.

In the quote above, Frank reflects on his experience of realising that he had achieved a lot of his deepest desires. This realisation changed his outlook on life in a way that made him more hopeful and less anxious for the future. When asked about the context of this joyful experience Frank reported that it was a "mental context" that was "on-going". The joyfulness Frank felt, therefore, appeared available to him whenever he happened to reflect on this realisation and 
newfound perspective. For Frank and many of the other participants, the experience of joy as something that is long lasting was thus connected to a sense of personal growth. It is important to recognise that Frank had initially begun to work towards the things that he desired but over time he became less proactive or forceful in achieving his dreams. When they came true, therefore, it was somewhat unexpected, which appeared to intensify the feeling of positivity.

Despite there being differences in the context in which participants felt joyful and the duration of this, there was always an overwhelming feeling of positivity. This experience of positivity was personal to the individual and what they perceived as important and enjoyable. This uncovered an important quality of the feeling of joyfulness for our participants; joy was the feeling of pure positivity and an absence of anything emotionally unpleasant or painful. In the moment of joy, everything in life felt magical, safe and positive, and this feeling could be momentary or it could be extended and expanding.

Willful Loss of Control. When feeling joyful, there was a desire or an impulse to be moving, and for some there was a struggle to remain still. Whether they were jumping, clapping or tapping a foot, the accounts suggested that a joyful individual is animated and lively. An allencompassing feeling of positivity and goodness in the participant's world created a profound sense of freedom and liberation, and they were compelled to move merrily throughout the space surrounding them. Embedded within this movement was a wilful and desired loss of control. According to the participants' accounts, a joyful individual wishes to move spontaneously, instinctively and without restriction or control. This unconstrained and uninhibited movement was an embodiment of the freedom and delight that was experienced when feeling joyful.

Both Margot and Jack described their experience of being joyful as childlike and playful. This captured their hyperactivity but also their lack of seriousness, concern or worry. 
I guess I turned into a little kid, skipping and holding onto my boyfriend's hand. I had the biggest grin on my face, and when I am happy and joyful I always wiggle my head *wiggles head* and turn into a child just like "LA LA LAAA", laughs.

I was very hyper (laughs) I suppose I was kind of acting like the boss, giving everyone instructions on what to do. I was just laughing and smiling, really just enjoying life. I was coming up with lots of silly ideas but I do that anyway so. I was being silly, jumping on the waterslide, being really playful, we were like little boys again.

In the act of skipping, smiling, laughing and jumping, both Margot and Jack shared a similar experience of feeling carefree when joyful. They were immersed in the present moment, unaware or careless of what others might think of their jolly spirit. The notion of being a child again, reveals a relaxed and stress-free nature, thus, in the moment of joy there was no demand for them to act in a manner than might be considered formal or mature. They could let go of the seriousness of life, and for a moment they felt young and untroubled. This highlights the sense of freedom, to say, be or act in whatever way feels natural when joyful. In that moment of joy there was no sense of restriction, both Margot and Jack as a result, actively and wilfully gave in to the feeling of no limit, moving and behaving freely with little regard of their appearance. Their engagement with the present feeling of joy was a complete mind-body experience.

In the quote below, Margot reflects on the difficulties she faced regarding the experience of joy during her musical performance. The expectation for her to be professional meant not interacting with her colleagues, moving freely or expressing any emotion.

Yeah that would have ruined it [the experience of joy], if I had to constrain it too much. If you constrain things you lose because joy is a free thing isn't it, if you put so many rules 
on it you are stamping it out really. It stamps out the fun. I needed to have a wiggle, not being able to turn around and smile at my friends when they played well put a damper on things. I had to control myself and I don't think joy should be controlled I think it should be free. When you are sad and you cry you can't stop yourself from crying and so when you are happy and you wiggle, you are going to wiggle, that's what I think. [Giggles].

Margot identifies a difficulty experiencing joy fully as a result of not being able to move or act freely during her performance. She also expresses displeasure in having to regulate her behaviour and argues that joy should not be restricted. Margot compares crying as a natural part of sadness to wiggling and movement as natural components of joy. This suggests that movement and freedom are essential to her full experience of being joyful. If there are restrictions or the perception that a childlike and playful nature is not acceptable in the given context, the experience of joy could be hindered. Margot's account also indicates a sense of choice as to whether or not she 'gave in' to joy. The experience of joy, therefore, was the feeling and embodiment of pure positivity and freedom, where the individual embraced the opportunity to exist in the present moment without the need for control.

When joy was long lasting, the participants still reported a wilful loss of control however this was not confined to a specific sensory environment. Instead, the participants experienced a sense of going with the flow, and trusting the nature of what happens in their lives. In this way, the desire to move freely was about letting go of the worries or anxieties that limit their experience of being, thus opening themselves up to the opportunities that appear as a result. 
Joy as Interpersonal. Although joy was meaningful in a very personal way for participants, the presence of others appeared to add an additional layer of meaning. Many of the participants suggested that being in the company of loved ones or interacting with them influenced their experience of joy in a way that either deepened their connection with those individuals or amplified their feeling of joyfulness. As briefly discussed in the analysis of Wilful Loss of Control, Margot's inability to interact with her colleagues, due to the pressure to be professional during her performance, restricted her experience of joy. This highlighted the importance that others can have in an individual's experience of being joyful.

In the quote below, Mia explores how the process of sharing a joyful experience with a loved one influenced her feelings for that individual:

It was nice being there with my brother because me and my brother have grown up listening to them [Coldplay] so maybe it was a bond thing between me and him, we are not that close but we kind of looked at each other and were like OH MY GOD and I felt closer to him then.

The concert that Mia and her brother attended was of a band they both equally adored. Mia explained that her and her brother did not necessarily have a close relationship. However, sharing a positive experience increased the connection and closeness that she felt towards him. Mia's account demonstrates the impact that shared experiences of being joyful can have on an individual's relationships. Alternatively, in the quotes below, Margot explores how being in the presence of a loved one, intensified her feeling of joy. This uncovers an interconnectedness 


\begin{abstract}
between the feeling of joy and relationships with others, as each appears to have a positive influence on the other.
\end{abstract}

For Margot, having her boyfriend there with her when she finally got to go to London to see the musical that she dreamed of seeing for so long was a pivotal part of her experience of joy:

I started talking to my boyfriend again, we started comparing our best bits, even though we had the same experience we saw it from a different view so we were talking about that and he saw things differently to me and we shared it with each other as we were walking back. I remember it being freezing cold but it was fun though, it was a good end to the day.

Through reflecting on the musical with her significant other, Margot identified that she could further experience the joy that she felt "I got all excited again about all the best bits". Being able to talk to a loved one about the object of joy gave Margot the opportunity to explore and process her joyful experience. This discussion, as a result, appeared to reinforce the reality that her wish to see the musical had come true. Having her loved one with her, therefore, heightened her experience of joy because the discussion and interaction made it feel real. The influence that others appear to have thus indicates that, for the participants, joy was quite often a shared, social and interactive experience.

When reflecting on her experiences of joy, Margot recognised the importance of others in her ability to feel joyful:

When I am joyful I feel safe and loved. When you feel happy you are in your safe place with people you love. If you are stranded and lost you are not going to be happy are you? 
I think you have to be safe to be happy because happiness is so free you have to have the safety, you have to feel safe and loved before you can feel happy.

In the quote above, Margot explains that in order to feel positive, an individual needs to feel safe. One way in which emotional safety is created is through the presence of loved ones along with the feeling that we are supported and cared for. The emotional security that loved ones provide, thus, creates an environment in which an individual can feel free. This freedom of being, in turn enables the pure and wholesome feeling that is joy. In this way, others provide the safety to enable giving in to loss of control and freedom of expression.

\section{Discussion}

Analysis of the participants' accounts showed that often the experience of feeling joyful was one that included ascription of significant meaning to the object of joy, free movement of the self and interaction with others. Past research has tended to characterise joy as something that is temporary and not striven for (Cottrell, 2016). For the most part, the participants' descriptions of joy were in accordance with the finding that joy is fleeting. However, on some occasions joy was also described as continuous and expanding, thus supporting the previous finding that joy may be experienced in the moment but also for a longer duration (Watkins, Emmons, Greaves \& Bell, 2017). Findings from the current study also revealed that when the feeling of joy was shortlived, it was experienced as unintentional. The participants did not necessarily work towards it, thus is happened somewhat randomly. It is important to recognise though that despite the participants not appearing to make any conscious effort towards achieving a goal, there was some sense of intentionally losing themselves in the experience as the participants wilfully celebrated the feeling of joy via clapping, skipping and so on. When the feeling of being joyful was long-lived the participants did appear to have put in some effort to achieving something they 
deeply desired. This supports Volf's (2015) proposal that joy is experienced in response to news or an event that indicates the individual's life is, in their view, going well. In both short-lived and long-lived experiences of joy, the participants did not strictly set out to feel a particular emotion. However, in long-lived experiences of joy there was some degree of the individual trying to achieve a personal goal, but this was not the case when the feeling of joy was short-lived. These findings further suggest that there is some variation in the duration of feeling joyful, thus uncovering complexity in the experience of this phenomenon, particularly concerning the person's intentions prior to and during the feeling of joy.

Typically, past studies have found that a less intense experience of positivity, which occurs when an individual has accomplished something they have worked towards, has been labelled by research participants as "happiness" (Cottrell, 2016). At first glance, it might seem as though the long-lived experiences of joy provided by the current participants, closely resemble these experiences of "happiness" and that similar experiences are being labelled differently by research participants in different studies. However, by taking a closer look at the present findings, we can see that despite the participants putting in effort to achieve something that they desired, the perceived probability of this happening was low. Thus, similarly to the short-lived experiences of joy, long-lived experiences of joy were also unexpected. This notion of unexpectedness is not something past research has identified in the feeling of happiness, and may be partly what distinguishes experiences of joy. Both long and short-lived experiences of joy were absent of any worry, stress or sadness. These findings suggest that the intense positivity and freedom that participants experienced when joyful may be influenced by the unexpectedness of the feeling. Therefore, the findings support existing research that suggests there is some 
distinction between experiences labelled as joyfulness and experiences labelled as happiness (Sloan, 2011).

In line with Hoffman, Kaneshiro \& Compton (2012)'s research, loved ones appeared to play a crucial role in the feeling of being joyful for the majority of the experiences of joy explored by the participants in the current study. This contrasts with what Holmes (2015) identifies as the typical understanding of emotion as an internally generated phenomenon. Our findings instead support the viewpoint that emotions are often produced interactively with others (Burkitt, 2014), in keeping with Baumeister \& Leary’s (1995) view of humans as fundamentally social beings. However, this is not to suggest that joy could not be experienced when alone.

\section{Limitations and Future Research}

The participants within this study were all young people of a similar age. It is important to recognise that experiences of joy may vary across culture, age, gender identification, occupation and time, as do other emotional experiences (Parkinson, Fischer \& Manstead, 2005). In consideration of this, it might be valuable for future qualitative research on the experience of joy to include samples of participants from varying demographic variables. This will help to further provide a contextualised understanding of feeling joyful, thus, shedding light on what it means to experience joy.

Phenomenological research does not claim, or indeed seek, generalizability in the sense used in quantitative research. What it can offer, though, is insights that may shed new light on a topic that can enrich theoretical thinking for other types of research (Brooks \& King, 2017). Thus the main findings of this study could help quantitative researchers to refine how they 
examine the concept of joy - for example, by distinguishing between short and long-term types of experience.

\section{Conclusion}

Movement, a sense of freedom and interaction with loved ones appeared pivotal to the experience of joy for the four participants in this study. The analysis uncovered an interconnection across these aspects of joy. For example, being in the company of loved ones created an environment of emotional safety enabling the feeling of freedom and desire to act playfully. Existing studies have found similar qualities of joy but not necessarily identified their interaction with one another. The present study is original in its detailed examination of the nature of joyful experiences, with a strong focus on how the feeling of joy is related to its object. In so doing, it offers fresh insights that add to our understanding of the phenomenon and provide an impetus for further research. 


\section{References}

Averill, J. R. (1982). Anger and aggression: An essay on emotion. NY: Springer-Verlag.

Barbalet, J. (2006). Emotion. Contexts, 5(51), 51-53.

Barrett, L. F. (2006). Are emotions natural kinds? Perspectives on Psychological Science, 1, 2858.

Baumeister, R. F., \& Leary, M. R. (1995). The need to belong: Desire for interpersonal attachments as a fundamental human motivation. Psychological Bulletin, 117(3), 497529.

Brooks, J. and King, N. (2017). (Eds.) Applied Qualitative Research in Psychology. London: Palgrave.

Burkitt, I. (2014). Emotions and social relations. London: Sage.

Close, H. T. (1981). The experience of joy. Journal of Pastoral Care \& Counseling, 35(3), 177187.

Cottrell, L. (2016). Joy and happiness: A simultaneous and evolutionary concept analysis. Journal of Advanced Nursing, 72(7), 1506-1517.

Csikszentmihalyi, M. (1991). Flow: The psychology of optimal experience. New York: HarperPerennial.

Dowling, M. (2007). From husserl to van manen. A review of different phenomenological URL: http:/mc.manuscriptcentral.com/ripos Email: journalpospsych@ucdavis.edu 
approaches. International Journal of Nursing Studies, 44(1), 131-142.

Eatough, V., \& Smith, J. (2006). I was like a wild wild person: Understanding feelings of anger using interpretative phenomenological analysis. British Journal of Psychology, 97(4), 483-498.

Finlay, L. (2012). Debating Phenomenological Methods. In N. Friesen, C. Henriksson \& T. Saevi (Eds.), Hermeneutic phenomenology in education (pp. 17-37). Rotterdam: Sense Publishers.

Frijda, N. (2005). Emotion experience. Cognition and Emotion, 19(4), 473-497.

Giorgi, A. (1985). Phenomenology and Psychological Research. Pittsburgh, PA: Duquesne University Press.

Hoffman, E., Kaneshiro, S., \& Compton, W. C. (2012). Peak-experiences among Americans in midlife. Journal of Humanistic Psychology, 52(4), 479-503.

Holmes, M. (2015). [Review of the book Emotions and social relations, by I. Burkitt]. Information, Communication \& Society, 18(12), 1430-1433.

Husserl, E. (1962). Phenomenological psychology (J. Scanlon, Trans.). London: Routledge. (Original work published, 1925).

King, N. (2012). Doing template analysis. In G. Symon and C. Cassell (Eds.), Qualitative organizational research: core methods and current challenges (pp.426-451). London: 
Maslow, A. H. (1964). Religions, values, and peak-experiences (Vol. 35). Columbus: Ohio State University Press.

Merleau-Ponty, M. (1962). Phenomenology of perception (C. Smith, Trans.). London: Routledge \& Kegan Paul. (Original work published 1945).

Parkinson, B. (1996). Emotions are social. British Journal of Psychology, 87(4), 663-683.

Parkinson, B., Fischer, A. H. \& Manstead, A. S. R. (2005). Emotions in social relations: Cultural, group and interpersonal processes. NY: Psychology Press.

Racher, F. E., \& Robinson, S. (2003). Are phenomenology and postpositivism strange bedfellows? Western Journal of Nursing Research, 25(5), 464-481.

Rich, G. J. (2017). The promise of qualitative inquiry for positive psychology: Diversifying methods. The Journal of Positive Psychology, 12(3), 220-231.

Robbins, B. D. (2006). An empirical, phenomenological study: Being joyful. In C.T. Fischer (Ed.), Qualitative research methods for psychologists: Introduction through empirical studies (pp.173-211). Academic Press.

Robinson, O.C. (2014) Sampling in interview-based qualitative research: a theoretical and practical guide, Qualitative Research in Psychology, 11(1), 25-41

Sartre, J. (1971). Sketch for a theory of the emotions. (M. Phillip, Trans.). London: Methuen. 
(Original work published, 1939).

Seligman, M.E.P. \& Csikszentmihalyi, M. (2000). Positive psychology: An introduction. American Psychologist, 55(1), 5-14.

Slaby, J (2008). Affective intentionality and the feeling body. Phenomenology and the Cognitive Sciences, 7(4), 429-444.

Sloan, H. K. (2011). Joy. The Journal of Value Inquiry, 45(4), 419-431. doi:10.1007/s10790011-9297-6.

Smith, J. A., Flowers, P. and Larkin, M. (2009). Interpretative Phenomenological Analysis: Theory, Research, Practice. London: Sage.

van Deurzen, E. (1997). Everyday Mysteries existential dimensions of psychotherapy. London: Routledge.

van Manen, M. (Ed.). (2016). Researching lived experience: Human science for an action sensitive pedagogy, 2e. London, Ont: Althouse Press.

Volf, M. (2015). The crown of the good life: A hypothesis. In M. Volf \& J. E. Crisp (Eds.), Joy and human flourishing: Essays on theology, culture, and the good life (pp. 127-136). Minneapolis, MN: Fortress Press.

Watkins, P. C., Emmons, R. A., Greaves, M. R., \& Bell, J. (2017). Joy is a distinct positive URL: http:/mc.manuscriptcentral.com/rpos Email: journalpospsych@ucdavis.edu 
1

2

3

4

5

6

7

8

9

10

11

12

13

14

15

16

17

emotion: Assessment of joy and relationship to gratitude and well-being. The Journal of Positive Psychology, 1-18.

\section{Tables}

Table 1. van Manen's Methodological Activities

1. Turning to a phenomenon which seriously interests us and commits us to the world.

2. Investigating experience as we live it rather than conceptualise it.

3. Reflecting on the essential themes which characterise the phenomenon.

4. Describing the phenomenon through the art of writing and rewriting.

5. Maintaining a strong and oriented pedagogical relation to the phenomenon.

6. balancing the research context by considering parts and whole. 
Table 2. Participant Details

\begin{tabular}{|c|l|l|}
\hline Pseudonym and Age & Example 1 & Example 2 \\
\hline 1. Mia (21) & Going to a Coldplay & Changing course at \\
& university \\
\hline 2. Frank (21) & Change in perception & Achieving bucket list \\
& grandmother's 80" & \\
& birthday party & Taking part in a \\
\hline 3. Margot (22) & "Lees Ming the performance & musical performance \\
& &
\end{tabular}


1

2

3

4

5

6

7

8

9

10

11

12

13

14

15

16

17

18

19

20

21

22

23

24

25

26

27

28

29

30

31

32

33

34

35

36

37

38

39

40

41

42

43

44

45

46

47

48

49

50

51

52

53

54

55

56

57

58

59

60

\begin{tabular}{|l|l|l|}
\hline & partner & \\
\hline 4. Jack (21) & $\begin{array}{l}\text { Weekend spent with } \\
\text { friends during summer }\end{array}$ & Holiday with friends \\
& & \\
\hline
\end{tabular}

